\title{
MENGENAL MARGA LUTJANUS, SALAH SATU KOMODITAS UNGGULAN DALAM PERIKANAN TANGKAP
}

\author{
Oleh \\ Selvia Oktaviyani ${ }^{1}$ )
}

\begin{abstract}
NOTES ABOUT LUTJANUS, ONE OF MAIN COMMODITIES IN CAPTURE FISHERIES. The snapper, genus Lutjanus are commercially important fish species, distributed in tropical to temperate regions all over the world. This group is mostly reef associated marine fishes and several deep-water $(>100 \mathrm{~m})$ species. Genus Lutjanus contains the largest number of species, i.e. 72 species in the world and almost 33 species in Indonesian waters. The snappers are dioecious and gonochoristic organisms, this means that they have separate sexes and the sexual differentiation remains constant throughout their life span. They are carnivorous and the diet consist mainly of small fishes, crustaceans, mollucas, and pelagic urochordata.
\end{abstract}

\section{PENDAHULUAN}

Marga Lutjanus dikenal dengan nama lokal ikan kakap atau snappers dalam bahasa Inggris. Keseluruhan jenis dalam marga ini merupakan sumber daya ikan yang penting, baik secara komersial maupun rekresional. Pada umumnya, ikan kakap dimanfaatkan sebagai ikan konsumsi, dijual dalam bentuk segar atau fillet. Selain itu, jenis ikan ini juga dijadikan sebagai ikan target dalam wisata pancing di beberapa perairan Indonesia.

Pada tahun 2011, volume produksi ikan kakap di seluruh perairan Indonesia mencapai 118.608 ton. Penangkapan terhadap jenis ikan ini mengalami peningkatan sebesar $6,21 \%$ sejak tahun 2001 hingga 2011 (KKP, 2012). Hingga saat ini, pencatatan data produksi perikanan tangkap untuk ikan kakap masih sangat terbatas pada jenis tertentu

\footnotetext{
$\overline{{ }^{1)} \text { Pusat Penelitian Oseanografi, LIPI }}$
}

atau disatukan menjadi satu kelompok. Hal ini disebabkan oleh sulitnya identifikasi di lapangan atau pada saat pendaratan dilakukan bersamaan dengan jenis ikan lainnya.

Hingga tahun 2018, jenis ikan dalam marga Lutjanus berjumlah 72 jenis yang menyebar di perairan seluruh dunia (Froese \& Pauly, 2018). Dari jumlah tersebut, Allen \& Erdmann (2012) menyebutkan bahwa terdapat sekitar 30 jenis ikan yang hidup di perairan Indonesia, sedangkan Allen \& Adrim (2003) mencatat terdapat 32 jenis. Jenis ikan yang tidak disebutkan dalam Allen \& Erdman (2012) adalah Lutjanus bitaeniatus, L. fuscencens dan L. johnii. Sebaliknya $L$. maxweberi tidak tercatat dalamAllen \&Adrim (2003). Berdasarkan publikasi tersebut, maka setidaknya terdapat 33 jenis ikan kakap, marga Lutjanus di perairan Indonesia. Untuk 
lebih mengenal kelompok jenis ikan ini, maka tulisan ini akan mengulas secara terperinci mengenai karakter umum, reproduksi, habitat, kebiasaan makanan, serta penangkapan dan pemanfaatan dari ikan kakap, marga Lutjanus.

\section{KARATERISTIK MORFOLOGI}

Ciri utama dari marga Lutjanus adalah memiliki badan yang pipih, punggung lebih tinggi dan kepala agak lancip. Profil kepala bagian atas membulat hingga agak condong atau miring, sedangkan untuk profil kepala bagian bawah berbentuk rata. Mata berukuran sedang dan cenderung lebih dekat kepada profil kepala bagian atas dibandingkan profil bagian bawah. Ciri utama lainnya adalah memiliki mulut yang besar dan terletak di ujung depan kepala (terminal). Beberapa gigi taring, seperti gigi kaninus biasanya hadir di ujung rahang anterior. Selain pada rahang, gigi juga ditemukan

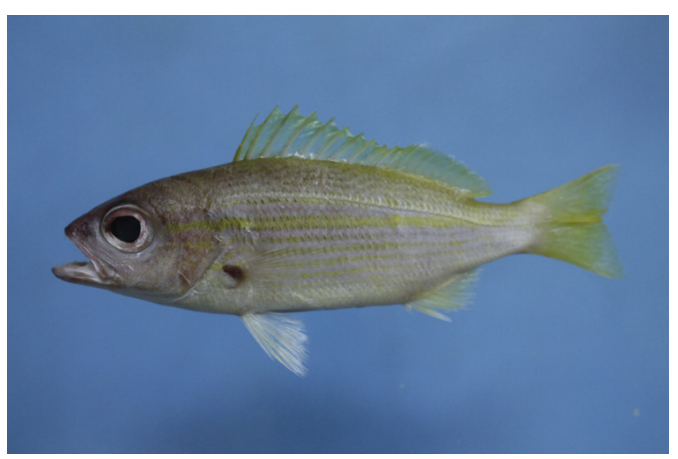

di bagian vomer dan palatin (Anderson \& Allen, 2001).

Sisik berukuran kecil hingga sedang dan masuk dalam tipe ktenoid. Gurat sisi lengkap dan tidak terputus, dari belakang operkulum hingga ke dekat sirip ekor. Sirip punggung memiliki 10 hingga 12 duri keras, serta 11-16 duri lemah, sedangkan sirip dubur dengan 3 duri keras dan 7-11 duri lemah. Tulang lengkung insang pertama memiliki kurang dari sama dengan 20 tapis insang (Anderson \& Allen, 2001).

Warna tubuh ikan kakap, marga Lutjanus sangat bervariasi, dari warna merah, merah muda, kuning, dan sebagainya. Selain itu, pola atau corak juga beragam seperti bercak-bercak, garis, bercak besar dan pola lainnya (Anderson \& Allen, 2001). Berikut ini adalah contoh dari anggota marga Lutjanus yang umum ditemukan di perairan Indonesia (Gambar $1)$.

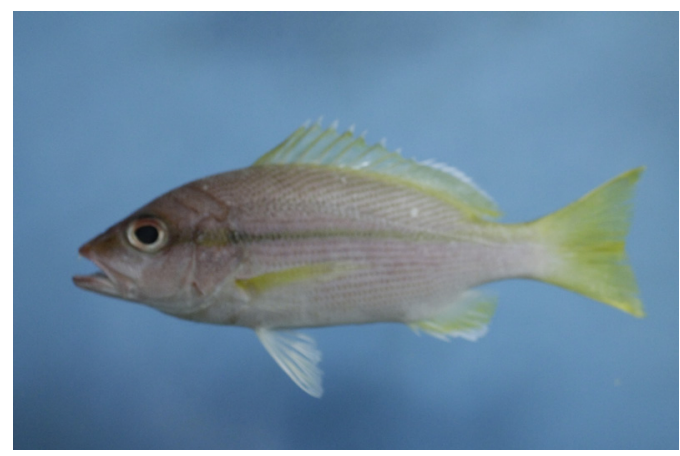

Gambar 1. Lutjanus Lutjanus (kiri) dan Lutjanus vitta (kanan) yang ditangkap di sekitar Perairan Teluk Jakarta (Foto : Oktaviyani, 2014).

Panjang maksimum untuk setiap jenis ikan kakap sangat beragam, mulai dari $20 \mathrm{~cm}$ hingga $120 \mathrm{~cm}$, tergantung dari jenisnya (Tabel 1). Perbedaan ukuran panjang juga sering ditemui pada jenis yang sama di perairan yang berbeda. Seperti yang terjadi pada ikan kakap merah, L. malabaricus di Laut Jawa 
dilaporkan memiliki ukuran panjang cagak maksimum $94 \mathrm{~cm}$ (Wahyuningsih et al., 2013), sedangkan di Australia, Newman (2002) menemukan pada ukuran maksimum panjang cagak $80,2 \mathrm{~cm}$.

Banyak faktor yang menyebabkan perbedaan ukuran panjang ikan, seperti faktor genetik, kondisi fisiologis, umur, jenis kelamin, keturunan, energi dan kondisi lingkungan masing-masing perairan. Faktor-faktor tersebut akan memengaruhi cepat lambatnya pertumbuhan ikan, sehingga berdampak pada adanya variasi ukuran panjang (Effendie 1997; Fry \& Milton 2009; Schwartzkopf \& Jr 2017). Selain itu, adanya pengaruh dari faktor eksternal, seperti karakteristik dan selektivitas alat tangkap yang digunakan untuk penelitian juga menyebabkan perbedaan ukuran tersebut.

Tabel 1. Panjang total maksimum dan habitat ikan kakap, marga Lutjanus.

\begin{tabular}{|c|c|c|c|c|}
\hline No & Nama ilmiah & $\begin{array}{c}\text { Panjang } \\
\text { total } \\
\text { maksimum } \\
\text { (TL) } \\
\end{array}$ & Habitat & Sumber \\
\hline 1 & L. argentimaculatus & $120 \mathrm{TL}$ & $\begin{array}{l}\text { Mangrove hingga terumbu karang } \\
1-120 \mathrm{~mm}\end{array}$ & $\begin{array}{l}\text { Allen \& Erdmann } \\
\text { (2012) }\end{array}$ \\
\hline 2 & L. bengalensis & $30 \mathrm{TL}$ & $\begin{array}{l}\text { Terumbu karang, laguna dan lereng } \\
\text { terluar } 10-30 \mathrm{~m}\end{array}$ & $\begin{array}{l}\text { Allen \& Erdmann } \\
\text { (2012) }\end{array}$ \\
\hline 3 & L. biguttatus & $20 \mathrm{TL}$ & $\begin{array}{l}\text { Terumbu karang, laguna, lereng } \\
\text { menuju laut 5-30 m }\end{array}$ & $\begin{array}{l}\text { Allen \& Erdmann } \\
\text { (2012) }\end{array}$ \\
\hline 4 & L. bitaeniatus & $30 \mathrm{TL}$ & Terumbu karang 40-80 m & Froese \& Pauly, 2018 \\
\hline 5 & L. bohar & $75 \mathrm{TL}$ & Laguna, terumbu terluar 5-150 m & $\begin{array}{l}\text { Allen \& Erdmann } \\
(2012)\end{array}$ \\
\hline 6 & L. boutton & $28 \mathrm{TL}$ & $\begin{array}{l}\text { Terumbu karang, laguna, lereng } \\
\text { terluar 3-20 m }\end{array}$ & $\begin{array}{l}\text { Allen \& Erdmann } \\
\text { (2012) }\end{array}$ \\
\hline 7 & L. carponotatus & $40 \mathrm{TL}$ & $\begin{array}{l}\text { Terumbu karang, laguna, lereng } \\
\text { terluar } 1-35 \mathrm{~m}\end{array}$ & $\begin{array}{l}\text { Allen \& Erdmann } \\
\text { (2012) }\end{array}$ \\
\hline 8 & L. decussatus & $30 \mathrm{TL}$ & $\begin{array}{l}\text { Terumbu karang, laguna, lereng } \\
\text { terluar 5-35 m }\end{array}$ & $\begin{array}{l}\text { Allen \& Erdmann } \\
\text { (2012) }\end{array}$ \\
\hline 9 & L. dodecacanthoides & $25 \mathrm{TL}$ & Terumbu karang, $1-30 \mathrm{~m}$ & $\begin{array}{l}\text { Allen \& Erdmann } \\
\text { (2012) }\end{array}$ \\
\hline 10 & L. ehrenbergii & $35 \mathrm{TL}$ & Terumbu karang dan estuary, 1-20 m & $\begin{array}{l}\text { Allen \& Erdmann } \\
\text { (2012) }\end{array}$ \\
\hline 11 & L. erythropterus & $55 \mathrm{TL}$ & $\begin{array}{l}\text { Estuari, Terumbu karang, laguna, } \\
\text { lereng terluar 3-35 m }\end{array}$ & $\begin{array}{l}\text { Allen \& Erdmann } \\
\text { (2012) }\end{array}$ \\
\hline 12 & L. fulviflamma & $35 \mathrm{TL}$ & $\begin{array}{l}\text { Shoreline reef, laguna, lereng } \\
\text { terluar } 1-75 \mathrm{~m}\end{array}$ & $\begin{array}{l}\text { Allen \& Erdmann } \\
\text { (2012) }\end{array}$ \\
\hline 13 & L. fulvus & $40 \mathrm{TL}$ & $\begin{array}{l}\text { Terumbu karang, laguna, lereng } \\
\text { terluar } 1-35 \mathrm{~m}\end{array}$ & $\begin{array}{l}\text { Allen \& Erdmann } \\
\text { (2012) }\end{array}$ \\
\hline 14 & L. fuscencens & $40 \mathrm{TL}$ & Air tawar, hingga kedalaman $15 \mathrm{~m}$ & Froese \& Pauly, 2018 \\
\hline 15 & L. gibbus & $50 \mathrm{TL}$ & $\begin{array}{l}\text { Laguna, lereng karang menuju ke } \\
\text { laut } 1-150 \mathrm{~m}\end{array}$ & $\begin{array}{l}\text { Allen \& Erdmann } \\
(2012)\end{array}$ \\
\hline 16 & L. johnii & $97 \mathrm{TL}$ & Hingga kedalaman $80 \mathrm{~m}$ & Froese \& Pauly, 2018 \\
\hline
\end{tabular}


19 L. lunulatus

20 L. Lutjanus

21 L. madras

22 L. malabaricus

23 L. maxweberi

24 L. mizenkoi

25 L. monostigma

26 L. quinquelineatus

27 L. rivulatus

28 L. rufolineatus

29 L. russelli

30 L. sanguineus

31 L. sebae

32 L. semicinctus

33 L. timorensis

34 L. vitta
35 TL Terumbu karang, laguna, lereng menuju laut 1-265 m

65 TL Terumbu karang, laguna, lereng terluar 2-80 m

35 TL Terumbu karang, lereng menuju ke laut, $10-30 \mathrm{~m}$

Allen \& Erdmann

(2012)

Allen \& Erdmann

(2012)

Allen \& Erdmann (2012)

30 TL Terumbu karang, lereng menuju ke Allen \& Erdmann laut, $10-90 \mathrm{~m}$

(2012)

30 TL Terumbu karang, lereng terluar $5-90 \mathrm{~m}$

Allen \& Erdmann (2012)

100 TL Pesisir dan karang menuju ke laut, 10-40 m (juvenile)

Allen \& Erdmann (2012)

20 TL Air tawar, estuary dan mangrove, 3-4 m

Allen \& Erdmann (2012)

26 TL Terumbu karang, 10-20 m hingga perairan $150 \mathrm{~m}$

Allen \& Erdmann (2012)

55 TL Terumbu terluar, formasi karang yang besar. $5-50 \mathrm{~m}$

Allen \& Erdmann (2012)

30 TL Terumbu karang, laguna, lereng karang terluar, 2-40 m

80 TL Terumbu karang 2-50 m

Allen \& Erdmann

(2012)

Allen \& Erdmann (2012)

28 TL Terumbu karang 10-50 m

Allen \& Erdmann

(2012)

45 TL Pesisir dan terumbu karang 3-80 m

Allen \& Erdmann

(2012)

100 TL Kedalaman 9-100 m

80 TL Pesisir dan lepas pantai, substrat berpasir hingga $100 \mathrm{~m}$

Froese \& Pauly, 2018

Allen \& Erdmann

(2012)

35 TL Laguna dan terumbu karang 5-35 m Allen \& Erdmann

(2012)

50 TL Perairan dalam 30-150 m

Allen \& Erdmann

(2012)

40 TL Pesisir dan terumbu tepi 10-72 m

Allen \& Erdmann (2012)

\section{Kebaruan Marga Lutjanus}

Dalam kurun waktu 11 tahun terakhir ini, telah ditemukan tiga jenis ikan marga Lutjanus yang baru di dunia, yaitu $L$. alexandrei, L.indicus dan $L$. papuensis. L. alexandrei dideskripsikan pertama kali oleh Moura R.L dan K.C Lindeman pada tahun 2007. Ciri khusus yang membedakan ikan ini dengan jenis lainnya adalah dari corak warna dan beberapa karakter di bagian badan. $L$. alexandrei memiliki warna tubuh dan sirip yang kemerahan, terdapat tujuh garis vertikal putih pada permukaan tampak dorsal dan adanya bintik hitam di pipi dan insang (saat hidup berwarna biru) (Moura \& Lindeman, 2007).

L. indicus dan L. papuensis dideskripsikan oleh Allen et al. pada tahun 2013. Dua ikan jenis baru tersebut, 
ditemukan di perairan yang berbeda, yaitu di Samudera Hindia ( $L$. indicus) dan sebelah barat Samudera Pasifik ( $L$. papuensis). Ciri yang menjadi pembeda antara $L$. indicus dengan jenis ikan lain adalah adanya pola pewarnaan yang berbeda, dan terdapat tujuh garis yang sempit berwarna kuning kecokelatan pada sisi lateral yang miring ke arah dorsal dan posterior. Sementara itu, untuk L. papuensis memiliki pola pewarnaan (bagian dorsal berwarna kebiruan sampai abu-abu, bagian bawah dari sisi lateral, sirip dubur dan sirip perut berwarna kuning cerah), interorbital lebih lebar, tubuh lebih ramping, dan profil snoutforehead lebih datar (Allen et al., 2013). Jenis ini ditemukan pertama kali di Teluk Cendrawasih, Papua Barat, sehingga dikatakan oleh Allen dan Erdmann (2012) sebagai The Papuan Snapper.
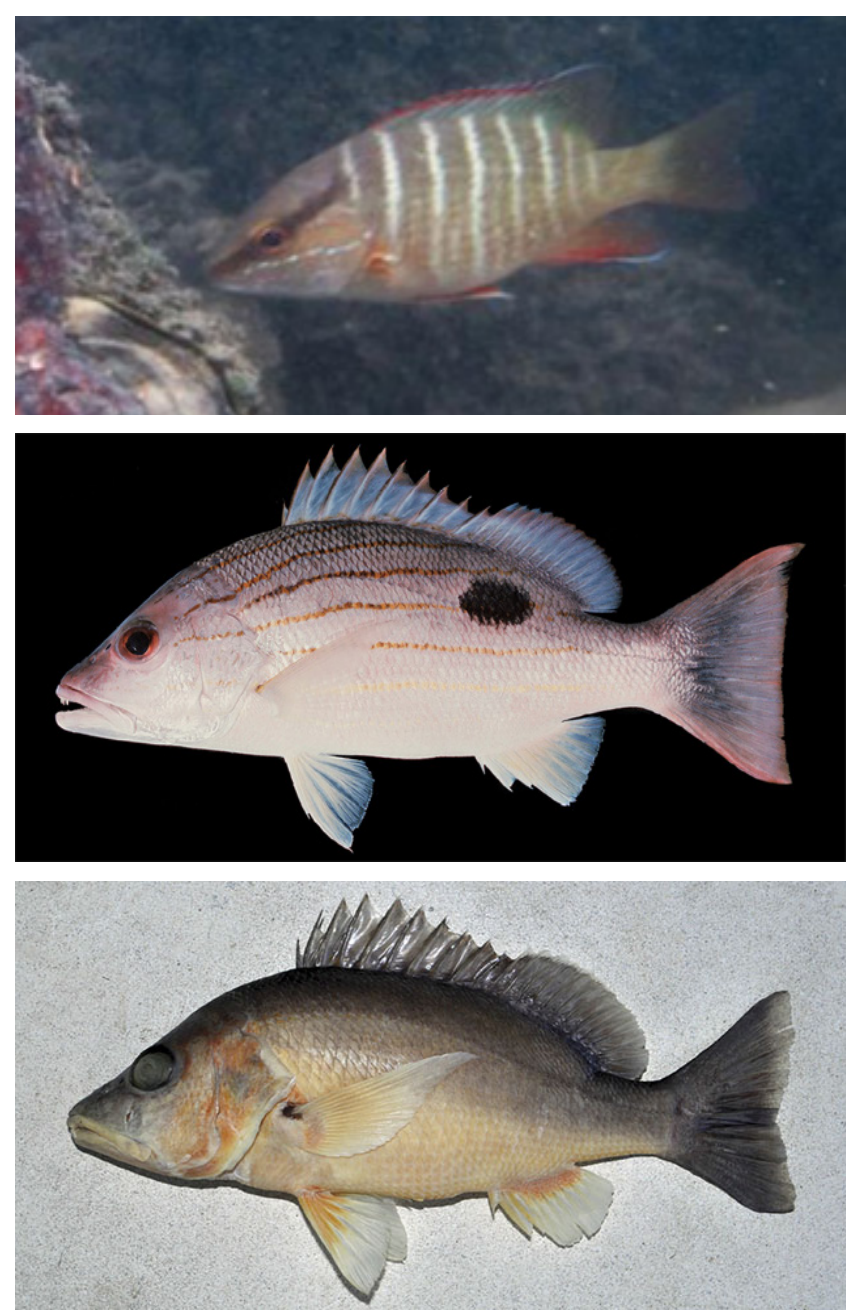

Gambar 2. L. alexandrei (atas), L. indicus (tengah) dan L. papuensis (bawah) (Froese \& Pauly, 2018). 


\section{Habitat}

Setiap jenis ikan dalam marga Lutjanus memiliki preferensi habitat yang berbeda (Tabel 1), namun sebagian besar hidup di sekitar kawasan terumbu karang. Ikan-ikan tersebut hidup secara berkelompok, baik dalam jumlah besar atau kecil serta terkadang hidup soliter (Allen, 1985). Jenis ikan kakap yang benar-benar hidup soliter adalah $L$. rivulatus, L. sebae dan L. timorensis (Allen \& Erdmann, 2012). Distribusi habitat marga Lutjanus meliputi daerah sebelah barat Pasifik Utara, termasuk Okinawa, Jepang, Indo West Pacific: Afrika timur hingga Fiji, timur Pulau Ryukyu, selatan Australia (Allen, 1985).

\section{Reproduksi}

Sistem reproduksi ikan kakap, marga Lutjanus bersifat gonokoris, yaitu alat kelamin jantan dan betinanya terpisah pada individu yang berbeda (Anderson \& Allen, 2001). Kondisi ini menunjukkan bahwa sejak dari muda telah ada perbedaan antara jantan dan betina, dimana perbedaan tersebut bersifat tetap hingga dewasa (Effendie, 1997). Kelamin atau gonad ikan jantan umumnya berwarna putih dan kenyal, sedangkan untuk gonad betina berwarna kuning hingga agak kemerahan dan akan tampak butiran telur jika telah mencapai kematangan kelamin. Kelompok ikan ini akan mencapai kematangan kelamin pada ukuran 40-50\% dari panjang maksimumnya (Grimes, 1987).

Pada umumnya, penentuan jenis kelamin dan tingkat kematangan gonad (TKG) ikan kakap dilakukan secara visual, yaitu dengan cara memperhatikan perubahan morfologi pada gonad jantan dan betina. Penelitian yang dilakukan oleh Oktaviyani \& Kurniawan (2017) juga menentukan jenis kelamin dan TKG L. vitta secara visual, dimana masingmasing kategori mengacu pada Holden \& Raitt (1974) (Tabel 2). Perbedaan antara gonad jantan dan betina ditunjukkan pada Gambar 2. 
Tabel 2. Tingkat kematangan gonad ikan kakap, Lutjanus vitta (Holden \& Raitt, 1974).

\begin{tabular}{|c|c|c|c|}
\hline \multirow{2}{*}{$\begin{array}{c}\text { Tingkat } \\
\text { kematangan }\end{array}$} & \multirow{2}{*}{ Keadaan } & \multicolumn{2}{|c|}{ Keterangan } \\
\hline & & Ovari & Testes \\
\hline I & Belum matang & $\begin{array}{l}\text { Ovari kira-kira } 1 / 3 \text { panjang } \\
\text { rongga badan, bening, dan } \\
\text { berwarna kemerahan. Telur } \\
\text { tidak terlihat dengan mata } \\
\text { telanjang. }\end{array}$ & $\begin{array}{l}\text { Testes berukuran } 1 / 3 \text { panjang } \\
\text { rongga badan dan berwarna } \\
\text { keputihan. }\end{array}$ \\
\hline II & Perkembangan & $\begin{array}{l}\text { Ovari kira-kira } 1 / 2 \text { panjang } \\
\text { rongga badan, bening/jernih. } \\
\text { Telur tidak terlihat dengan } \\
\text { mata telanjang. }\end{array}$ & $\begin{array}{l}\text { Testes berukuran } 1 / 2 \text { panjang rongga } \\
\text { badan dan berwarna ke-putihan, } \\
\text { kurang lebih simetris. }\end{array}$ \\
\hline III & Pematangan & $\begin{array}{l}\text { Ovari kira-kira } 2 / 3 \text { panjang } \\
\text { rongga badan. Ovari } \\
\text { berwarna kuning kemerahan, } \\
\text { kelihatan butiran. }\end{array}$ & $\begin{array}{l}\text { Testes berukuran } 2 / 3 \text { panjang } \\
\text { rongga badan, lembut, dan ber- } \\
\text { warna keputihan sampai krem. }\end{array}$ \\
\hline IV & Matang & $\begin{array}{l}\text { Ovari memenuhi rongga } \\
\text { badan dan berwarna merah } \\
\text { jambu/jingga dengan } \\
\text { pembuluh darah yang terlihat } \\
\text { jelas di permukaannya. } \\
\text { Terlihat telur yang masak dan } \\
\text { tembus cahaya. }\end{array}$ & $\begin{array}{l}\text { Testes memenuhi rongga badan } \\
\text { dan berwarna keputihan/krem dan } \\
\text { lembut. }\end{array}$ \\
\hline V & Mijah salin & $\begin{array}{l}\text { Ovari mengerut sampai } \\
\text { menjadi kira-kira } 1 \frac{1}{2} \text { panjang } \\
\text { rongga badan. Ovari dapat } \\
\text { mengandung sisa-sisa telur, } \\
\text { gelap atau jernih. }\end{array}$ & $\begin{array}{l}\text { Testes mengerut sampai menja-di } \\
1 / 2 \text { panjang rongga badan. Dinding- } \\
\text { dinding kendur. }\end{array}$ \\
\hline
\end{tabular}
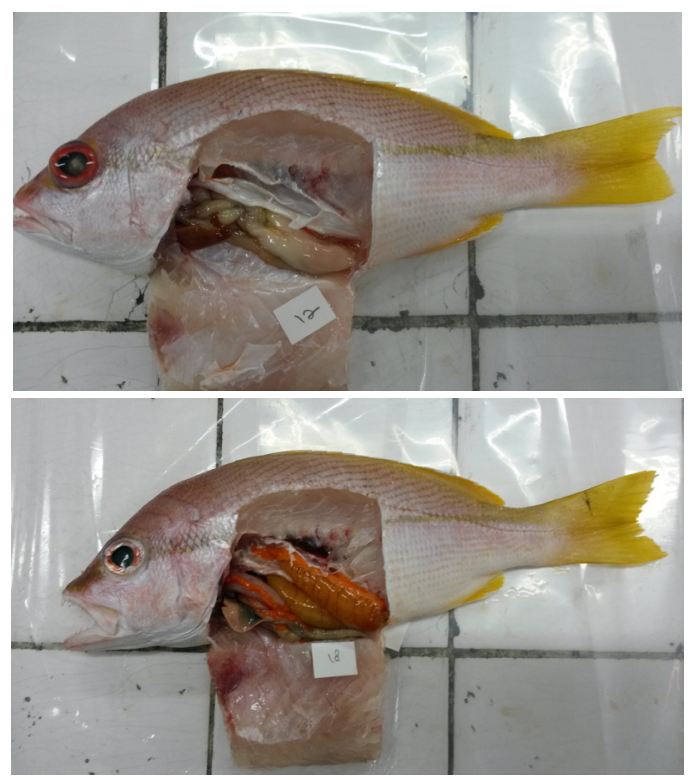

Gambar 3. L. vitta jantan (atas) dan L. vitta betina (bawah) (Foto: Oktaviyani, 2014). 
Pemijahan ikan kakap, marga Lutjanus dilakukan beberapa kali dalam sepanjang tahun (Anderson \& Allen, 2001). Jumlah telur yang diproduksi oleh betina kelompok ini sangat besar. Hal demikian merupakan salah satu ciri dari telur yang tidak dijaga oleh indukannya, sehingga keberhasilannya tergantung pada kondisi perairan, substrat penempel dan juga pemangsaan. Jumlah telur $L$. malabaricus di Perairan Sape berkisar antara 29.100-643.366 butir dan 54.618862.674 butir di perairan Kupang dengan ukuran diameter oosit antara 500-600 mikrometer (Andamari et al., 2004). Sementara itu, L. gibbus dan L. kasmira di India memiliki nilai fekunditas 46.774130.698 butir dan 33.752-225.850 butir secara berurutan (Anand \& Pillai, 2002). Fekunditas L. gibbus di perairan Selatan Banten sebesar 14.050-596.243 butir, dengan rata-rata 170.869 butir (Prihatiningsih, et al., 2017). L. vitta di India dilaporkan memiliki fekunditas relatif berkisar antara $222.016 \pm$ 28.543 dan $521.482 \pm 67,044$ telur/ikan (Ramachandran et al., 2014).

Ikan kakap, Marga Lutjanus akan beruaya ketika melakukan pemijahan (migration spawner) ke beberapa tempat, seperti daerah mangrove, laguna atau lereng karang yang berhubungan langsung dengan lautan lepas (Johannes, 1978). Ikan-ikan tersebut akan membentuk kelompok yang besar pada waktu dan tempat tertentu saat akan melakukan pemijahan (Claro \& Lindeman, 2003).

Informasi mengenai daerah pemijahan ikan kakap dapat diketahui melalui pengamatan terhadap bukti langsung dan tidak langsung. Claro \& Lindeman (2003) menyebutkan bahwa bukti langsung terdiri atas pengamatan terhadap ekstraksi gamet secara bersamaan di antara beberapa individu, identifikasi telur yang terhidrasi atau identifikasi terhadap folikel setelah ovulasi. Sementara itu, bukti tidak langsung adalah mencakup informasi dari nelayan terkait adanya agregasi pada saat sebelum dan saat terjadi pemijahan. Informasi tersebut harus dievaluasi dengan hati-hati, agar tidak terjadi bias atau kesalahpahaman. Informasi mengenai daerah agregasi pemijahan merupakan informasi yang sangat penting dalam kegiatan pengelolaan perikanan. Melalui informasi ini, dapat dibuat sebuah aturan mengenai pembatasan penangkapan pada waktu dan tempat agregasi suatu jenis ikan.

\section{Kebiasaan Makanan}

Ikan kakap, marga Lutjanus merupakan predator yang aktif mencari makan pada malam hari dan dikategorikan sebagai ikan karnivora, yaitu pemakan daging. Menurut Anderson \& Allen (2001), makanan kelompok ini adalah ikan, krustasea (khususnya udang, kepiting, lobster, stomatopoda), moluska (gastropoda, cephalopoda) dan urochordata pelagis.

\section{Penangkapan dan Pemanfaatan}

Pada umumnya nelayan di sekitar perairan Indonesia menangkap ikan kakap dengan menggunakan berbagai macam alat, antara lain dengan menggunakan 
pancing ulur, pancing rawai, trawl atau perangkap. Disebutkan dalam beberapa publikasi, sebagian besar ikan kakap yang ditangkap oleh nelayan di Perairan Laut Jawa bagian timur dan Perairan Teluk Jakarta, masih berukuran kecil atau belum matang gonad (Wahyuningsih et al. 2013; Oktaviyani \& Kurniawan, 2017).

Kondisi demikian harus mendapat perhatian khusus, karena jika dibiarkan akan berpeluang menyebabkan terjadinya tangkap lebih pertumbuhan (growth overfishing), yaitu penurunan stok ikan akibat ikan-ikan muda banyak tertangkap, sehingga tidak ada kesempatan ikan-ikan tersebut tumbuh dewasa dan tidak bisa mengimbangi penyusutan stok karena kematian alami.

Pemanfaatan ikan kakap oleh masyarakat sangat beragam, yaitu dijual langsung dalam bentuk segar atau dikeringkan asin. Harga jual ikan kakap berbeda setiap jenisnya. Jenis yang memiliki harga jual tinggi adalah ikan kakap merah, di Pulau Weh jenis ini bisa mencapai Rp. 100.000/kg. Selain itu, ikan kakap marga Lutjanus juga sering dijadikan sebagai target utama dalam wisata pancing atau yang bersifat rekresional.

\section{PENUTUP}

Ikan kakap, marga Lutjanus merupakan ikan yang bernilai ekonomis penting. Kelompok ini ditangkap dan dimanfaatkan masyarakat sebagai ikan konsumsi atau yang bersifat rekresional. Penangkapan yang dilakukan secara terus menerus perlu mendapatkan perhatian khusus, agar pemanfaatan dilakukan secara lestari dan dapat menjamin keberlanjutan sumber daya ikan kakap.

\section{DAFTAR PUSTAKA}

Allen, G.R. 1985. FAO Species Catalogue. Vol. 6. Snappers of the world. An annotated and illustrated catalogue of lutjanid species known to date. FAO Fish. Synop. 125(6):208 p

Allen, G.R and M. Adrim. 2003.. Coral reef fishes of Indonesia. Zoological Studies, 42 (1): 1-72.

Allen, G.R. and M.V. Erdmann, 2012. Reef fishes of the East Indies. Perth, Australia: Universitiy of Hawai' $i$ Press, Volumes II. Tropical Reef Research. 1,292 pp.

Allen, G.R., W.T. White and M.V. Erdmann. 2013. Two new species of snappers (Pisces: Lutjanidae: Lutjanus) from the Indo-West Pacific. Journal of the Ocean Science Foundation, 6: 33-51.

Anand, P.E. V and N.G.K. Pillai. 2002. Reproductive biology of some common coral reef fishes of the Indian EEZ. Journal of the Marine Biological Association of India, 44 (1 \& 2): 122-135.

Andamari, R., D. Milton, T. Van der Velde and B. Sumiono. 2004. Pengamatan aspek biologi reproduksi ikan kakap merah 
(Lutjanus malabaricus) dari Perairan Sape dan Kupang. Jurnal Penelitian Perikanan Indonesia, 10 (4): 65-75.

Anderson, W.D. Jr and G.R. Allen, 2001. Lutjanidae. Jobfishes. p. 28402918. In K.E. Carpenter and V. Niem (eds.) FAO species identification guide for fishery purposes. The living marine resources of the Western Central Pacific. Vol. 5. Bony fishes part 3 (Menidae to Pomacentridae). FAO, Rome. 2840 - 2853

Claro, R and K. C. Lindeman. 2003. Spawning aggregation sites of snapper and grouper species (Lutjanidae and Serranidae) on the Insular Shelf of Cuba. Gulf and Caribbean Research, 14 (2): 91-106.

Effendie MI. 1997. Biologi Perikanan. Yayasan Pustaka Nusatama, Yogyakarta. $162 \mathrm{hlm}$.

Froese, R. and D. Pauly. Editors. 2018. FishBase. World Wide Web electronic publication. www.fishbase.org, version (06/2018).

Fry, G., D.A. Milton., T.V.D. Velde., I. Stobutzki., R. Andamari., Badrudin and B. Sumiono. 2009. Reproductive dynamics and nursery habitat preferences of two commercially important Indo-Pacific red snappers Lutjanus erythropterus and L. malabaricus. Fisheries
Sciences, 75 (1): 145-158.

Grimes, C.B. 1987. Reproductive biology of the Lutjanidae: a review. In: Polovina JJ, Ralston $\mathrm{S}$ (ed.). Tropical snappers and groupers: biology and fisheries management. Westview Press, Boulder and London. pp. 239294.

Holden, M.J. and D.F.S. Raitt. 1974. Manual of Fisheries Science. FAO Fisheries Technical Papers 115. 214 p.

Johannes, R.E. 1978. Reproductive strategies of coastal marine fishes in the tropics. Environmental Biology of Fishes, 3 (1): 65-84.

KKP. 2012. Statistik Perikanan Tangkap Indonesia, 2011. Kementrian Kelautan dan Perikanan, 12 (1):1-190.

Moura, R. L. and K.C. Lindeman. 2007. A new species of snapper (Perciformes: Lutjanidae) from Brazil, with comments on the distribution of Lutjanus griseus and L. apodus. Zootaxa, 1422(3): 31-43.

Newman, S.J. 2002. Growth rate, age determination, natural mortality and production potential of the scarlet seaperch, Lutjanus malabaricus Schneider 1801, off the Pilbara coast of northwestern Australia. Fisheries Research, 58(2): 215-225. 
Oktaviyani, S. dan W. Kurniawan. 2017. Aspek reproduksi ikan kakap Lutjanus vitta (Quoy \& Gainmard, 1824) di Teluk Jakarta dan sekitarnya. Jurnal Iktiologi Indonesia, 17(2): 215225.

Prihatingsih, M.M. Kamal, R. Kurnia dan A. Suman. 2017. Hubungan panjang-berat, kebiasaan makanan, dan reproduksi ikan kakap merah (Lutjanus gibbus: Famili Lutjanidae) di Perairan Selatan Banten. Bawal. 9 (1): 21-32.

Ramachandran, S., D.M. Ali, and B.C. Varghese. 2013. Age, growth and maturity of brownstripe red snapper Lutjanus vitta (Quoy \& Gaimard, 1824) from southwest coast of India. Journal of Marine Biology, 55 (2): 61-68.
Schwartzkopf, B.D. and J.H.C. Jr. 2017. Seasonal and sex differences in energy reserves of red snapper Lutjanus campechanus on natural and artificial reefs in the northwestern Gulf of Mexico. Fisheries Science, 83 (1): 1322.

Wahyuningsih, Prihatiningsih dan T. Ernawati. 2013. Parameter populasi ikan kakap merah (Lutjanus malabaricus) di perairan Laut Jawa bagian timur. Bawal, 5 (3): 175-179. 